\title{
Microbial Stereo Inversion of (R) 3 Chloro-1,2-Propandiol by Wickerhamomyces anomalous MGR6-KY209903
}

\author{
Suresh Kumarasamy 1,*(D), Vasuki Subramanian ${ }^{1}{ }^{(\mathbb{D})}$, Mathiyazhagan Narayanan ${ }^{1}$ (D), \\ Muthusamy Ranganathan 1 (D) \\ 1 PG and Research centre in Biotechnology, MGR College, Hosur, Tamilnadu, 635130, India \\ * Correspondence: sureshbioteck@yahoo.com;
}

Scopus Author ID 57195420982

Received: 20.04.2020; Revised: 7.05.2020; Accepted: 8.05.2020; Published: 12.05.2020

\begin{abstract}
Our interest has been focused on the production of chiral compounds by the method of enantioselective microbial transformations of prochiral starting material with yeast. The preliminary assimilation was exercised with Wickerhamomyces anomalous MGR6 grown on synthetic medium and observed assimilation by $\mathrm{pH}$ change of the medium.The specific rotation of (R-3- Chloro-1,2propanediol) was $-5\left(\mathrm{c}=2.5\right.$, in $\left.\mathrm{C}_{2} \mathrm{H}_{5} \mathrm{OH}\right)$ in conditions with enatiomeric excess of $85.6 \%$ Wickerhamomyces anomalous product. The structural and dynamic properties of R-3-Chloro-1,2propanediol in GCMS spectrum, the most prevailing compound among them retention time of 9.63 was obtained. The IR Spectrum, a shallow broad band at wavelength 3290.56 signifies the presence of O-H stretching, the narrow peak both at 1637.56 indicates the presence of $\mathrm{C}=\mathrm{O}$ stretching in conjugation with functional group of R- 3 Chloro-1,2-propanediol $\left(\mathrm{C}_{3} \mathrm{H}_{7} \mathrm{ClO}_{2}\right)$. The sharp peaks in HPLC spectrum of $\mathrm{R} 3$ Chloro-1,2-propanediol in the retention time peak were $2.47 \mathrm{~min}$ and concentration $100 \%$. These results concluded that the strain assimilated and sterio inversion of R-3-Chloro-1,2-propanediol via RS 3-chloro-1,2-propanediol. The possibility to produce optically active R-3-Chloro-1,2-propanediol was discussed.
\end{abstract}

Keywords: MCH-Monochlorohydrin; Wickerhamomyces anomalous MGR6 KY209903; enatiomeric excess; polarimeter; Biotransformation; Stereo inversion.

(C) 2020 by the authors. This article is an open access article distributed under the terms and conditions of the Creative Commons Attribution (CC BY) license (https://creativecommons.org/licenses/by/4.0/).

\section{Introduction}

The life science industry is a significant market for the pharmaceutical industry. The total revenue from trading in the pharmaceutical and agrochemical industries for the year 2018 is estimated to be in excess of US 150 billion, of which the greatest share comes from the pharmaceutical industry. Optically active intermediates used as chemical building blocks, auxiliaries, or advanced intermediates have an estimated fraction of $17 \%$ of the market. Selling of special intermediates is increasing at about $10-12 \%$ annually. Because of the increasing demand in the pharmaceutical industry for optically active intermediates, these compounds have a disproportionate share with $12 \%$ annually. About $78 \%$ of the active intermediates compounds that pharmaceutical companies have in the pipeline are chiral, and it is estimated that this fraction will increase, as the development of active compounds continues to be improved [1].

The optically active (R)-3-chloro-1,2-propanediol is a useful starting material for synthesizing a variety of 5 drugs and optically active compounds having physiological activity [2]. A process for the preparation of optically active 3-Chloro-1,2-propanediol which 
comprises cultivating in a medium containing racemate 3-Chloro-1,2-propanediol a bacterium and yeast, which, when cultivated in a medium containing racemate 3-Chloro-1,2-propanediol (Figure.1) as a sole carbon source, can grow and proliferate, has an ability to assimilate S(-)-3Chloro-1,2-propanediol preferentially compared to R-3-Chloro-1,2-propanediol and belongs to bacteria and yeast, or its culture cells and recovering R-3-Chloro-1,2-propanediol from the resulting culture broth [3].
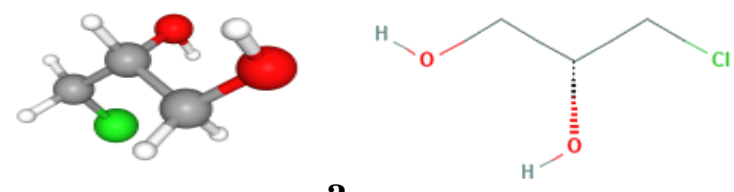

$\mathbf{a}$

Figure 1. (R)-3-Chloro-1,2-propanediol a) Interactive Chemical Structure Model; b) Chemical Structure Depiction.

Yeast can be used for a number of bioconversions [4].Large numbers of yeast species are currently recognized for their ability to utilize hydrocarbons as sole sources of carbon and energy listed 114 species and varieties of hydrocarbon-assimilating yeasts. Some of these have since been reduced to synonymy with other species. Species are found in the genera Candida, Debaryomyces (including Schwanniomyces and Wingea), Lodderomyces, Clavispora, Metschnikowia,Pichia, Stephanoascus, and Yarrowia basidiomycetous species are in genera Leucosporidium, Rhodosporidium,Sporidiobolus, Sporobolomyces, Rhodotorula, and Trichosporon. The discovery that some taxa are basidiomycetes has broadened perception of the nature of yeasts. This group is represented by numerous strains that were chosen and adapted for specific industrial fermentations [5].

Wickerhamomyces anomalus is a frequently found yeast species in natural environments (plants, soil, fruits, animals) and in various fermentations, and there are some beneficial effects that have been previously reported, such as functioning as an intermediate agent and intermediate producer [6-10].

Biotransformations technique is becoming increasingly popular in the pharmaceutical production of enantio and regiopure intermediates for the synthesis of complex organic compounds. Whole microbial cells can be used to carry out such specific chemical reactions that are otherwise difficult to achieve active synthetically [11].The reports an eco-friendly and efficient methodology for biotransformation of halohydrins to 3 Chloro 1, 2-propanediol using microbes. This procedure involves the addition of water avoiding the utilization of additional solvents and avoiding acidic and basic conditions to afford 3-Chloro-1,2-propanediol nearly yield about $68 \%$ without any need for any further purification so only a small amount of waste is generated [12].

In this paper, we report the properties of the assimilation and dehalogenation activities in Wickerhamomyces anomalus MGR 6 extracts and the conversion of (R)-Monochlorohydrin using the microbial resolution and characterization studies by polarimeter, FTIR, NMR, GCMS and HPLC.

\section{Materials and Methods}

\subsection{Culture collection.}

Identified yeast cultures were stored in PG and Research centre in Biotechnology, MGR College, Hosur, Tamilnadu, India. The pure culture of the strains was obtained under standard 
operating protocols [13]. The following Wickerhamomyces anomalus MGR 6 (KY209903) strain has been used for further experiments.

\subsection{Assimilation of 3 Chloro-1,2-propanediol in solid media.}

The isolate was subjected to primary screening for sorting out their ability for the degradation and assimilation for $(R, S)$-3Chloro-1,2-propanediol. Wickerhamomyces anomalus MGR 6 strain was streaked on to agar plates containing synthetic medium (Racemic 3Chloro-1,2-propanediol $-0.5 \mathrm{~g}$, diammonium sulfate- $0.5 \mathrm{~g}$, dipotassium hydrogen phosphate$0.1 \mathrm{~g}$,diammonium sulphate $-0.2 \mathrm{~g}$,sodium dihydrogen phosphate- $0.05 \mathrm{~g}$, Magnesium sulphate$0.05 \mathrm{~g}$,ferrous sulphate- $0.0001 \mathrm{~g}$, copper sulphate- $0.0001 \mathrm{~g}$, manganese sulphate- $0.0001 \mathrm{~g}$, agar$0.5 \mathrm{~g}$ bromothymol blue, $0.008 \mathrm{~g}-$ agar $/ 100 \mathrm{ml})(\mathrm{pH}-6.8)$ and incubated at $30^{\circ} \mathrm{C}$ for $48 \mathrm{hrs}$. After incubation period, the plates were observed for colour and $\mathrm{pH}$ change in the medium, which indicates the assimilation of $(R, S) 3$ Chloro-1, 2-propanediol [14].

\subsection{Conversion of optically active Monochlorohydrin.}

Wickerhamomyces anomalus MGR 6 seed culture $(5 \mathrm{ml})$ was inoculated into $2.5 \mathrm{~L}$ of the synthetic medium containing $2.0 \%(\mathrm{v} / \mathrm{v})(R, S)-3$ Chloro-1,2-propanediol as a sole source of carbon source in a $5 \mathrm{~L}$ fermenter,the culture broth was taken out and the cells were removed by centrifugation and to derive the supernatant alone. The $250 \mathrm{ml}$ medium was allowed to condense about $150 \mathrm{ml}$ using the rotary evaporator and extracted with $100 \mathrm{ml}$ ethyl acetate. The evaporation and extraction process was repeated thrice. Then it was dried on anhydrous magnesium sulphate and the solvent residue was distilled using vacuum evaporation (rotavap) to get a condensed syrup of optically active 3-Chloro1,2-propanediol [15].The optically active condensed syrup was further subjected to characterization studies by polarimeter, FTIR, NMR, GCMS and HPLC.

\subsection{Determination of specific rotatory power by polarimeter.}

The optical activity and specific rotatory power of condensed syrup were determined using JASCO-181 digital polarimeter at ambient temperature at NCL, Pune for standard procedure. The optical rotation was measured at the wavelength of the $\mathrm{D}$ line of sodium $(\lambda=589.3 \mathrm{~nm})$ at $20^{\circ} \mathrm{C}$, on a layer $1 \mathrm{dm}$ length. It was expressed in degrees. The reading, which appeared on the digital panel was noted and the calculated the optical rotation, purity of enantiomers using the formula given below. $\alpha_{\lambda}^{T}=\frac{\alpha}{I X C}$

2.5.GC-MS analysis.

The condensed syrup was separated by Perkin Elmer Clarus 680 GC-MS capillary column model Elite-5MS (30m X $0.25 \mathrm{~mm})$. The Gas chromatography was directly interfaced with Clarus 680 mass spectrometer with an interface temperature of $250^{\circ} \mathrm{C}$. Sample ionization was electron impact and was analysed by positive mode. Spectrum comparison was carried through NIST library [17]. 


\subsection{HPLC analysis.}

$50 \mu 1$ of condensed syrup R- 3 Chloro-1, 2-propanediol was taken separately in a clean dry glass vial with septum. The samples were allowed to run for about 25 minutes $\mathrm{C} 18$ column with mobile phase comprises of acetonitrile and water in the ratio 60:40v/v. Flow rate Flow rate was adjusted to $1 \mathrm{ml} / \mathrm{min}$. Detection-UV detection set to the range of $290 \mathrm{~nm}$. Finally,Retention time, peak area, Theo plate, tail factor and graph of the standard were recorded [18].

\subsection{FTIR analysis.}

The condensed $1 \mathrm{ml}$ syrup sample was mixed with $1 \mathrm{ml}$ of $\mathrm{KBr}$. Appropriate pressure was excreted to form a transparent pellet. FTIR spectra of the product were recorded from the spectral range of $400-4000 \mathrm{~cm}^{-1}$.

\subsection{NMR analysis.}

Sample concentration was adjusted to $50 \mathrm{Mm}$, instrument type is Bruker, $1 \mathrm{H}$ NMR of the and sample R-3 Chloro-1,2-propanediol was analyzed at the frequency of $600 \mathrm{MHz}$ and the $\mathrm{pH}$ was adjusted to the range of 7.00 , the temperature was adjusted to $25^{\circ} \mathrm{C}$ and the chemical shift reference used was TMS.1H NMR spectrum was allowed to run now, and the spectrum was acquired from it was recorded.

\subsection{Dehalogenation Liberation of chloride ions.}

For chloride liberation test, freshly prepared reagents (mercuric thiocynate solution and ferric alum solution) were used. Mercuric thiocyanate solution - adding $0.3 \mathrm{~g}$ of mercuric thiocyanate in $100 \mathrm{ml}$ of $95 \%$ ethyl alcohol and ferric alum solution - dissolving $6 \mathrm{~g}$ of ferric ammonium sulphate in $100 \mathrm{ml}$ of $6 \mathrm{~N}$ nitric acid. The experiment was carried out by transferring $10 \mathrm{ml}$ of the sample solution into sterile tubes. $1 \mathrm{ml}$ of mercuric thiocynate solution was added into each tubes and mixed well, then $2 \mathrm{ml}$ of ferric alum solution was added to it finally and vortexed for $15 \mathrm{~min}$. The reaction mixture was kept undisturbed for $15 \mathrm{~min}$.Visible colour change was observed, photographed against light background and the optical density was measured immediately after $15 \mathrm{~min}$ at A660nm. The total amount of chloride ions liberated was calculated [19].

\section{Results and Discussion}

\subsection{Assimilation reaction.}

The ability to degrade chloride ions of the isolates was assessed by basic visual identification of the medium in the. Flasks inoculated with, Wickerhamomyces anomalus MGR 6 were found dispersed in the medium and involves in changing the colour of the medium from dark green colour to pale greenish yellow coloured solution along with a reduction in the $\mathrm{pH}$ \{from nearly neutral stage-pH 6.8 to acidic condition $\mathrm{pH}-5.54$ \} and the same was observed in agar plate, media plate changes its colour from dark green colour to pale greenish yellow colour (Figure.2).In a previous repot of the employing various assimilation tests alone may be reliable as a universal means for identification. Numerous novel species, intraspecies variability of strains and conflicting assimilation profiles might be responsible for screening and identifications [19]. 


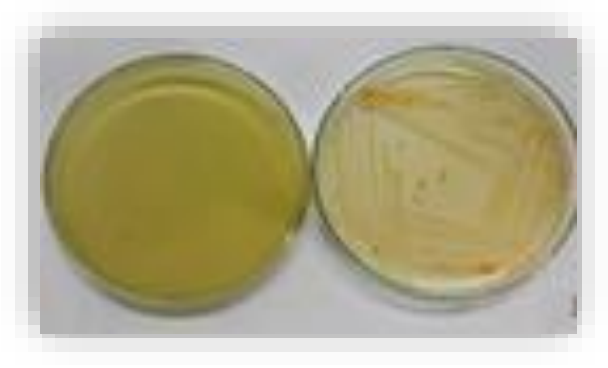

Figure 2. Assimilation efficiency of Wickerhamomyces anomalus MGR 6.

\subsection{Conversion.}

In the production medium incubated at fermentor condition Wickerhamomyces anomalous MGR6 exhibited an exponential growth rate of $1.929 \mathrm{~N}$ (Figure.3). The isolate Wickerhamomyces anomalous MGR6 liberated $1.323 \mathrm{ppm}$ of chloride ions from the medium, whereas \% yield of Wickerhamomyces anomalous was R-3-chloro-1,2-propanediol 66\%. In a previous study, the characterization and production of an intermediate by Wickerhamomyces anomalus strain PY189 was carried. The highest efficiency production was observed when the isolate was grown in a synthetic medium with chloride ions $1.323 \mathrm{ppm}$ with a statistical micelle concentration of $204 \mathrm{mg} / \mathrm{l}$ [20].

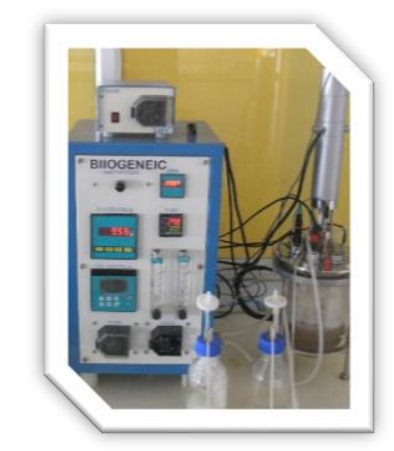

Figure 3. Conversion of optically active Monochlorohydrin in fermenter.

\subsection{Specific rotation and enatiomeric excess of the product.}

The assimilation and degradation of racemic 3-Chloro-1,2-propandiol ceased at 55\%, regardless of the concentration of racemic 3-Chloro-1,2-propandiol used $2 \%$.

Table 1. Specific rotation and enatiomeric excess of the product.

\begin{tabular}{c|c|c|c|c|c|c}
\hline S.No & Product Name & $\begin{array}{c}\text { Wavelength } \\
(\mathbf{n m})\end{array}$ & Solvent & $\begin{array}{c}\text { Concentration } \\
(\boldsymbol{\%})\end{array}$ & $\begin{array}{c}\text { Specific } \\
\text { Rotation } \\
\text { Pure (-7 })\end{array}$ & \% ee \\
\hline 1 & $\begin{array}{c}\text { R MCH (3- } \\
\text { Chloro-1,2- } \\
\text { propanediol std) }\end{array}$ & 589 & Ethanol & 2.5 & 0 & - \\
\hline 2 & MGR 6 product & 589 & Ethanol & 2.5 & $-5^{0}$ & 85.6 \\
\hline
\end{tabular}

Therefore, the conversion of R-3-Chloro-1,2-propandiol was considered to be stereospecific. The residual R-3-Chloro-1,2-propandiol was extracted with ethanol from the cultivation. The specific rotation of product (R-3-chloro-1,2-propanediol) was $-5^{0}(\mathrm{c}=2.5$, in $\mathrm{C}_{2} \mathrm{H}_{5} \mathrm{OH}$ ) with enatiomeric excess of $85.6 \%$ respectively (Table 1). A previous method for producing optically active 1,2-dio1s by microbial stereoinversion was developed. It was found 
that some microorganisms like yeast could convert only (R)-I,2-pentanediol in the racemate to the (S)-enantiomer, molar yield 93\%, enantiomeric excess $60 \%$ [21].

\subsection{GC-MS spectrum (R) 3 Chloro-1, 2-propanediol.}

GC-MS was used for determining the production recovery of 3 Chloro-1,2-propanediol. Components in GC-MS were recognized rapidly by its molecular ion, due to the higher specificity in SIM mode. The fragmentation patterns of detected components were given in table 2. The microbial extract yielded symmetrical peaks and excellent separation of components [22-23].

Table 2. Characteristic peaks of R-3 Chloro 1,2-propanediol MGR6 by GC-MS.

\begin{tabular}{c|c|c|l|c|c|c|c|c}
\hline Isolate & $\begin{array}{l}\text { Line } \\
\text { no. }\end{array}$ & $\begin{array}{l}\text { Hit } \\
\text { no. }\end{array}$ & Compound Name & Molecular weight & $\begin{array}{l}\text { CAS } \\
\text { No. }\end{array}$ & $\begin{array}{l}\text { Scan } \\
\text { no. }\end{array}$ & $\begin{array}{l}\text { Retention } \\
\text { time }\end{array}$ & $\begin{array}{l}\text { Molecular } \\
\text { formula }\end{array}$ \\
\hline MGR6 & 4 & 1 & $\begin{array}{l}\text { R-3 Chloro1,2 } \\
\text { propanediol }\end{array}$ & $110.539 \mathrm{~g} / \mathrm{mol}$ & $\begin{array}{c}96- \\
24-2\end{array}$ & 750 & 11.750 & $\mathrm{C}_{3} \mathrm{H}_{7} \mathrm{ClO}_{2}$ \\
\hline
\end{tabular}

The characteristic peaks were shown in Figure 4 and the retention time of (R) 3 Chloro1,2-propanediol was 9.693(scan number 750) obtained from MGR6 respectively. From the extracted product from the production medium inoculated with MGR6, total number of six components were detected the most prevailing compounds were 1,2-benzenediol(39\%), 4(Chloromethyl)-2-heptyl (53\%), 3-bromo-1,2-propanediol(64\%), propane,2-bromo-1-chloromethane (92\%), and the most prevailing compound detected was R-3 Chloro-1,2propanediol.CAS number, molecular weight and molecular formula for R-3 Chloro 1, 2propanediol were $96-24-2,110.539 \mathrm{~g} / \mathrm{mol}$ and $\mathrm{C}_{3} \mathrm{H}_{7} \mathrm{ClO}_{2}$ respectively.

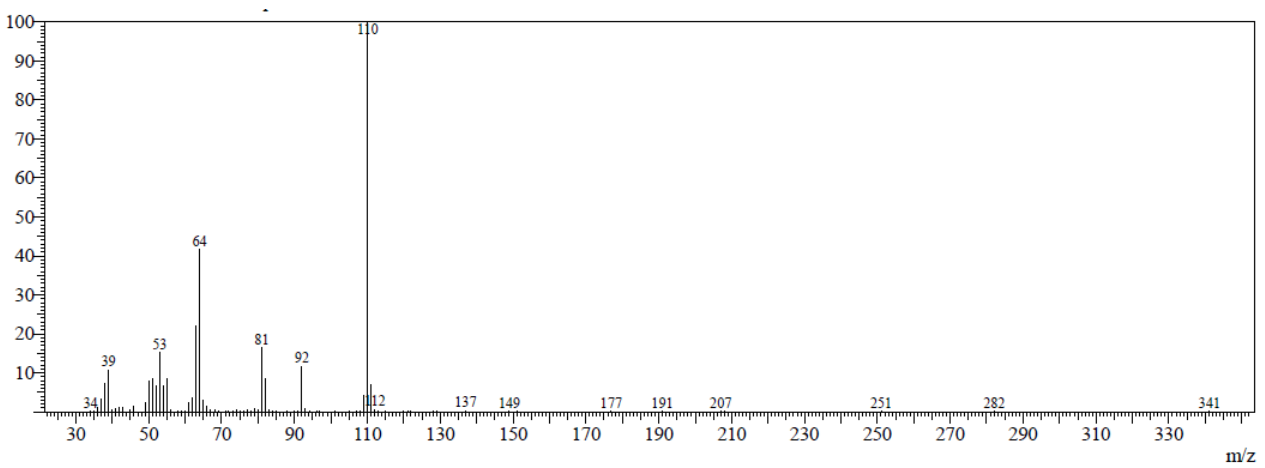

Figure 4. GCMS spectrum of optically active (R) 3 Chloro-1,2-propanediol (MGR 6).

\subsection{High Performance Liquid Chromatogrpahy spectrum of $(R) 3$ Chloro-1,2-propanediol}

The chromatographic separation was achieved using gradient separation methodology with the use of hexane and 2-propanol as mobile phase at the ratio of 60:40.The elution was carried out at the flow rate of $1.0 \mathrm{ml} / \mathrm{min}$. The sharp peaks obtained indicates the presence of $\mathrm{R}$ 3 Chloro-1,2-propanediol.The retention time peak are, theoretical plates were given in figure 5 and table 3.The sharp peaks in HPLC indicates the presence of 3 Chloro-1,2-propanediol.The retention time peak was (MGR 6) $2.47 \mathrm{~min}$, concentration was $100 \%$. Therefore, the optimum chromatographic conditions for resolving with a retention time of $3.81,11.17$, and 27.42, respectively. Obviously, the $\mathrm{R} 3$ Chloro-1,2-propanediol was separated from the derivatization agent and its dimer product by HPLC [24]. 


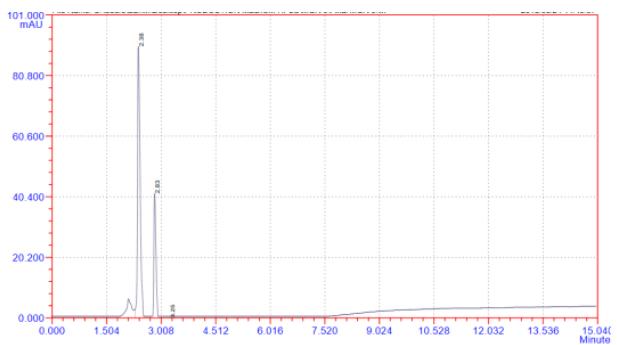

Figure 5. HPLC chromatogram of (R) 3 Chloro-1,2-propanediol obtained from MGR6.

Table 3. Characteristic feature of HPLC chromatogram of standard and (R) 3 Chloro-1,2-proanediol

\begin{tabular}{c|c|c|c|c|c|c}
\hline $\begin{array}{c}\text { Index } \\
\text { No. }\end{array}$ & Compound & $\begin{array}{c}\text { Retention } \\
\text { Time(min) }\end{array}$ & Peak area (\%) & Concentration & Theo. plate & Tail factor \\
\hline 1. & $\begin{array}{c}\text { Standard 3 } \\
\text { Chloro-1,2- } \\
\text { propanediol }\end{array}$ & 2.472 & 36457.5 & 100.00 & 295 & 0.01 \\
\hline 3. & MGR 6 & 2.47 & 19547.6 & 100 & 110 & 0.83 \\
\hline
\end{tabular}

3.6. FT-IR Spectrum of (R) 3 Chloro-1, 2-propanediol.

The IR Spectrum obtained from MGR6 produced a broad band at 3290.56 shows the presence of $\mathrm{O}-\mathrm{H}$ stretching, 1637.56 shows the presence of $\mathrm{C}=\mathrm{O}$ group, the bands at 1087.85 and 1045.42 signifies the presence of $\mathrm{C}-\mathrm{O}$ stretching. The functional group present in the sample solution was thus identified using the IR-spectral datas, that supports the presence of R-3 Chloro-1,2-propanediol $\left(\mathrm{C}_{3} \mathrm{H}_{7} \mathrm{ClO}_{2}\right.$ ) (Figure 6). In an earlier study, it has been observed that IR Spectrum obtained from yeast showed a shallow broad band at wavelength 3309.8 signifies the presence of $\mathrm{O}-\mathrm{H}$ stretching, the narrow peak at 1637.56 indicates the presence of $\mathrm{C}=\mathrm{O}$ stretching in conjugation with aryl ketones, the band at 1087.85 and 1045.42 indicates the C-O stretching that signifies the presence of alcoholic group [25-27].

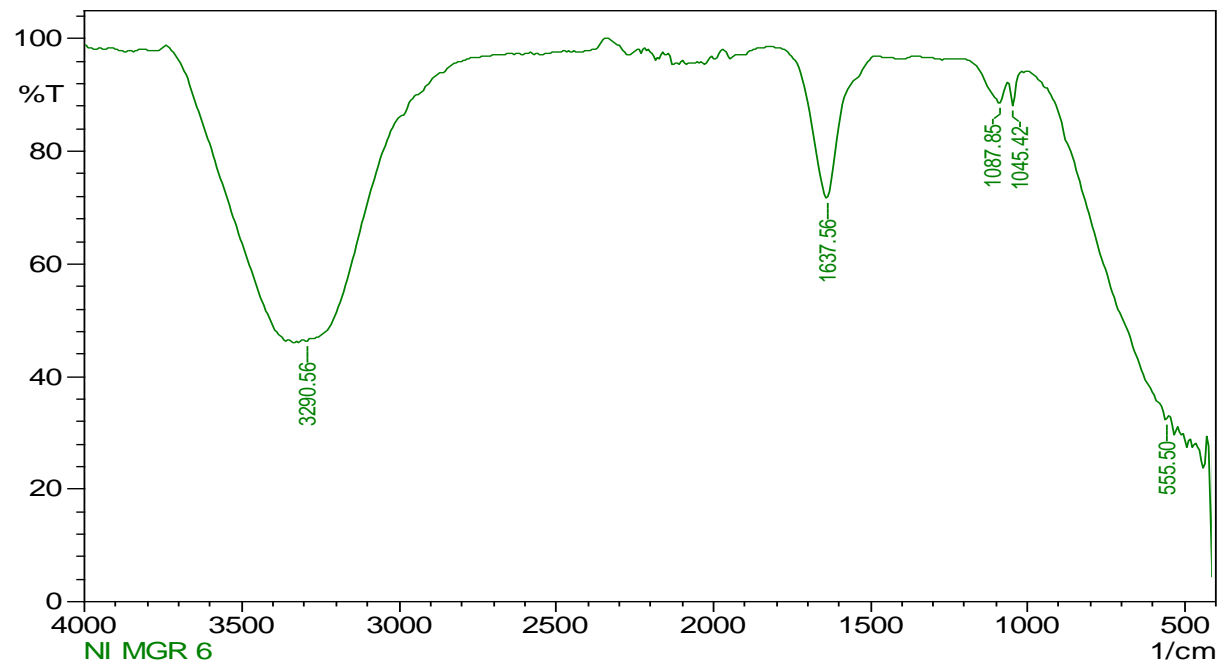

Figure 6. FT-IR Spectrum of (R) 3 Chloro-1, 2-propanediol obtained from isolates MGR6.

\subsection{NMR spectrum of (R) 3 Chloro-1,2-propanediol.}

R-3-Chloro-1,2-propanediol, colorless oil.1H NMR(400 MHz, DMSO-d6): $\delta 5.12$ $\left(1 \mathrm{H}, \mathrm{d}, \mathrm{CHOH}\right.$,exchangeable with $\left.\mathrm{D}_{2} \mathrm{O}\right) ; 4.73\left(1 \mathrm{H}, \mathrm{t}, \mathrm{CH}_{2} \mathrm{OH}\right.$, exchangeable with $\left.\mathrm{D}_{2} \mathrm{O}\right) ; 3.67-3.62$ $\left(2 \mathrm{H}, \mathrm{m}, \mathrm{CH}_{2} \mathrm{Cl}\right) ; 3.53-3.50$ (1H, m, $\left.\mathrm{CHOH}\right) ; 3.39-3.35\left(2 \mathrm{H}, \mathrm{m}, \mathrm{CH}_{2} \mathrm{OH}\right)$ (Figure 7).

Previously reported the establish the position of the chlorine released from DCP, proton NMR was performed, and chemical shifts were read and recorded for reaction mixtures 
containing enzyme, ferricyanide and DCP. NMR spectra three signals an intermediate product was assigned to 2-chloroacrolein. The time course of its aldehyde proton measure (9.31 ppm) displayed the same trend as the two protons (6.72 and $6.57 \mathrm{ppm})$ [28].

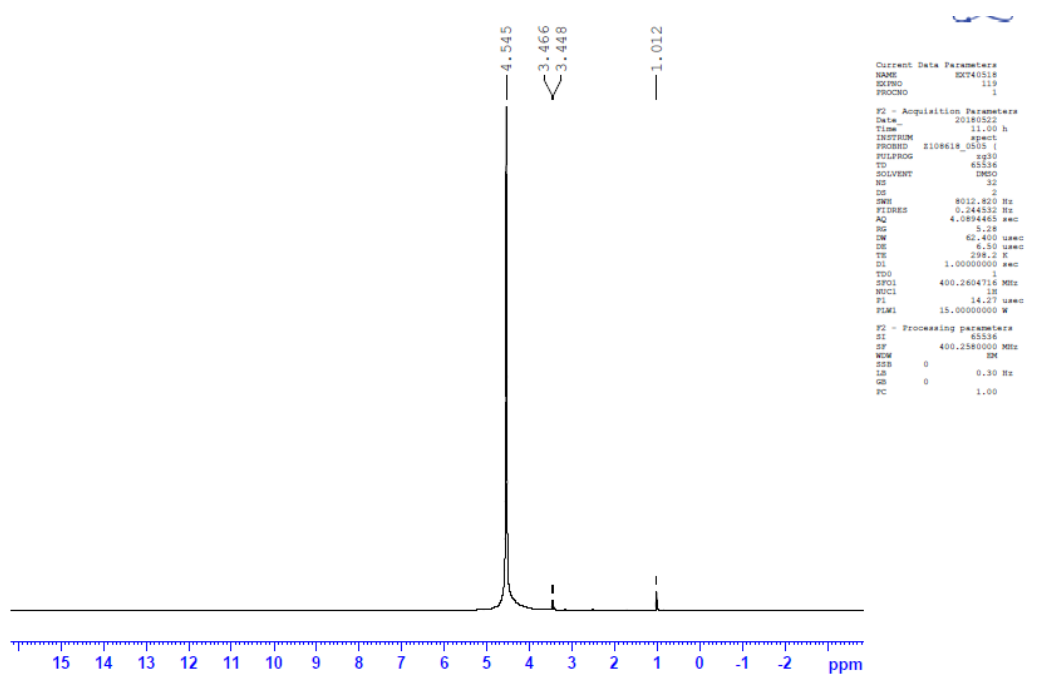

Figure 7. NMR Spectrum of (R) 3 Chloro-1, 2-propanediol obtained from isolates MGR6.

\section{Conclusions}

It was found that an effective method for the preparation of pure optically active (R)-3-Chloro 1,2-propanidol was established based on assimilation and degradation with Wickerhamomyces anomalus MGR6 (KY209903). It can be concluded that subjecting low priced (RS) -3-Chloro 1,2-propanidol to the action of Wickerhamomyces anomalus MGR6 (KY209903) to selectively metabolizing (R)-3-Chloro 1,2-propanidol. The specific rotation of the R-MCH obtained was $-5^{0}$ that the confirmation of (R) form and its optical purity was found to be $85.6 \%$ enantiomeric excess and produced $(\mathrm{R})$ form 16.2g of Monochlorohydrin.

\section{Funding}

The authors would like to thank Science and Engineering Research Board, Department of Science and Technology,Governement of India, New Delhi, India (Young Scientist Project, Ref. No.- YSS/2014/000733) for financial assistance.

\section{Acknowledgments}

The authors would like to thank, PG and Research Centre in Biotechnology, MGR College, Hosur, Tamilnadu for their technical support.

\section{Conflicts of Interest}

The authors declare no conflict of interest.

\section{References}

1. Ahmed, S.; Islam, S.; Ullah, B.; Biswas, S.K.; Azad, A.S.; Hossain, S. A Review Article on Pharmaceutical Analysis of Pharmaceutical Industry According to Pharmacopoeias. Orient $J$ Chem 2020, 36, http://dx.doi.org/10.13005/ojc/360101. 
2. Küppers, J.; Rabus, R.; Wilkes, H.; Christoffers, J. Optically Active 1-Deuterio-1-phenylethane Preparation and Proof of Enantiopurity. European Journal of Organic Chemistry 2019, 2019, 2629-2634, https://doi.org/10.1002/ejoc.201900121.

3. Huy, P.H. Lewis Base Catalysis Promoted Nucleophilic Substitutions - Recent Advances and Future Directions. European Journal of Organic Chemistry 2020, 2020, 10-27, https://doi.org/10.1002/ejoc.201901495.

4. Pham, J.V.; Yilma, M.A.; Feliz, A.; Majid, M.T.; Maffetone, N.; Walker, J.R.; Kim, E.; Cho, H.J.; Reynolds, J.M.; Song, M.C.; Park, S.R.; Yoon, Y.J. A Review of the Microbial Production of Bioactive Natural Products and Biologics. Frontiers in Microbiology 2019, 10, https://doi.org/10.3389/fmicb.2019.01404.

5. Rajesh, K.S. Yeast Species Mediated Bioprocesses and Bio-Products for Biotechnological Application. Journal of Biotechnology and Biomedical Science 2019, 2, 1-11, https://doi.org/10.14302/issn.25766694.jbbs-19-2684.

6. Chai, C.Y.; Huang, L.N.; Cheng, H.; Liu, W.J.; Hui, F.L. Wickerhamomyces menglaensis f.a., sp. nov., a yeast species isolated from rotten wood. Int J Syst Evol Microbiol 2019, 69, 1509-1514, https://doi.org/10.1099/ijsem.0.003350.

7. Fan, G.; Teng, C.; Xu, D.; Fu, Z.; Liu, P.; Wu, Q.; Yang, R.; Li, X. Improving ethyl acetate production in Baijiu manufacture by Wickerhamomyces anomalus and Saccharomyces cerevisiae mixed culture fermentations. Food Microbiology 2019, 1, 1-11, https://doi.org/10.1155/2019/1470543.

8. Cecarini, V.; Cuccioloni, M.; Bonfili, L.; Ricciutelli, M.; Valzano, M.; Cappelli, A.; Amantini, C.; Favia, G.; Eleuteri, A.M.; Angeletti, M.; Ricci, I. Identification of a Killer Toxin from Wickerhamomyces anomalus with $\beta$-Glucanase Activity. Toxins 2019, 11, 568, https://doi.org/10.3390/toxins11100568.

9. Padilla, B.; Gil, J.V.; Manzanares, P. Challenges of the Non-Conventional Yeast Wickerhamomyces anomalus in Winemaking. Fermentation 2018, 4, 68, https://doi.org/10.3390/fermentation4030068.

10. Diaz-Rincon, D.J.; Duque, I.; Osorio, E.; Rodriguez-Lopez, A.; Espejo-Mojica, A.; Parra-Giraldo, C.; Quevedo-Hidalgo, B. Production of recombinant Trichoderma reesei Cellobiohydrolase II in a new expression system based on Wickerhamomyces anomalus. Enzyme Research 2017, https://doi.org/10.1155/2017/6980565.

11. Hegazy, M.E.; Mohamed, T.A.; ElShamy, A.I. Microbial biotransformation as a tool for drug development based on natural products from mevalonic acid pathway: A review. $J$ Adv Res 2015, 6, 17-33, https://doi.org/10.1016/j.jare.2014.11.009.

12. Mahon, S.M.; Beekman, J. 3-Chloro-1,2-propanediol (3-MCPD), 2-chloro-1,3-propanediol (2-MCPD) and glycidyl esters in infant formula: a review. Current Opinion in Food Science 2019, 30, 67-72, https://doi.org/10.1016/j.cofs.2019.05.005.

13. Vasuki, S.; Suresh, K. Scanning Electron Imaging and Quantitative Spectral analysis of colony growth on Candida tropicalis MGR1,Clavispora lusitaniae MGR5, Wickerhamomyces anomalus MGR6 and Candida albicans MGR9. Research Journal of Biotechnology 2019, 14, 37-53.

14. Suzuki, T.; Kasai,NP.; Yamamoto, R.; Minamiura, N. Production of highly optically active (R)-3-chloro-1, 2-propanediol using a bacterium assimilating the (S)-isomer. Appl. Microbiol. Biotechnol 1993, 40, 273278, https://doi.org/10.1007/BF00170380.

15. Suzuki, T.; Kasai, N.; Yanamoto, R.; Minamiura, N. Isolation of a bacterium assimilating (R)-3-chloro-1,2propanediol and production of (S)-3-chloro-1,2-proPanediol using microbial resolution. J.Ferment. Bioeng 1992, 73, 443-448, https://doi.org/10.1016/0922-338X(92)90135-H.

16. Kim, S.; Zhang, X. Discovery of false identification using similarity difference in GC-MS-based metabolomics. J. Chemom 2015, 29, 80-86, https://doi.org/10.1002/cem.2665.

17. Nakamura, T.; Yu, F.; Mizunashi, W.; Watanabe, I. Microbial transformation of prochiral 1, 3-dichloro-2propanol into optically active 3-chloro-1,2-propanediol. Agric. Biol. Chem 1991, 55, 1931-1933, https://doi.org/10.1080/00021369.1991.10870882.

18. Iwasaki, I.; Utsumi, S.; Ozawa, Takejiro, O. New Colorimetric Determination of Chloride using Mercuric Thiocyanate and Ferric Ion. Bulletin of The Chemical Society of Japan. Bull Chem. Soc. Jpn 1952, 25, 226226, https://doi.org/10.1246/bcsj.25.226.

19. Kwolek-Mirek, M.; Zadrag-Tecza, R. Comparison of methods used for assessing the viability and vitality of yeast cells. FEMS Yeast Res 2014, 14, 1068-79, https://doi.org/10.1111/1567-1364.12202.

20. Dejwatthanakomola, C.; Anuntagoolb, J.; Morikawac, M.; Thaniyavarna, J. Production of biosurfactant by Wickerhamomyces anomalus PY189 and its application in lemongrass oil encapsulation. Scienceasia 2016, 42, 252-258, https://doi.org/10.2306/scienceasia1513-1874.2016.42.252.

21. Hasegawa, J.; Ogura, M.; Tsuda, S.; Maemoto, SI.; Kutsuki, H.; Ohashi, T. High-yield Production of Optically Active 1,2-Diols from the Corresponding Racemates by Microbial Stereoinversion. Agric. Bioi. Chern 1990, 54, 1819-1827, https://doi.org/10.1080/00021369.1990.10870226.

22. Retho,C.; Blanchard, F. Determination of 3-chloropropane-1,2-diol as its 1,3-dioxolane derivative at the $\mu \mathrm{g} \mathrm{kg}-1$ level: Application to a wide range of foods. Journal Food Additives \& Contaminants 2005, 22, 1189-1197, https://doi.org/10.1080/02652030500197680. 
23. Ponnaiah, P.; Shukri, H.; Muruganandham, C.; Narendrakumar, G.; Samrot, AV. Utilization of palm oil mill effluent and clindamycin for optimization of polyhydroxy [r] alkanoates production. Biointerface Research in Applied Chemistry, 2020,10, 4740 - 4746, https://doi.org/10.33263/BRIAC101.740746.

24. Chaib, M.; Ayat, M.; Rahmouni, A. Poly (para-acid phenol-D-Glucose): resin for the removal of fecal coliforms and Escherichia coli Safia Miloudi. Biointerface Research in Applied Chemistry, 2018,8,30093015.

25. Tamilvanan,S.; Gill, S.; Kaur, I.; Rahman, SNR.; Pawde,DM.; Katari,O.; Hmingthansanga,V.; Sekharan,TR. Candidiasis management: current status of allopathic drugs and utility of coriander-based oilless emulsions, Letters in Applied NanoBioScience, 2019, 8, 586-590, https://doi.org/10.33263/LIANBS83.586590.

26. Rhlid, R.B.; Jean, P.;Talmon.; Laurent, B.; Fay.; Juillerat, M.A. Biodegradation of 3-Chloro-1,2-propanediol with Saccharomyces cerevisiae. Journal of Agricultural and Food Chemistry 2004, 52, 6165-6169, https://doi.org/10.1021/jf048980k.

27. Zhang, Z.; Gao, B.; Zhang, X.; Jiang, Y.; Xu, X.; Yu, L. Formation of 3-Monochloro-1,2-propanediol (3MCPD) Di- and monoesters from Tristearoylglycerol (TSG) and the potential catalytic effect of Fe2+ and Fe3+. Journal of Agricultural and Food Chemistry 2015, 63, 1839-1848, https://doi.org/10.1021/jf5061216.

28. Pinto, L.; Da Silva, E.T.; De Souza, M.V.N. Eco-friendly and highly efficient multigram synthesis of 3chloro-1,2-propanediol using sonochemistry. Mediterranean Journal of Chemistry 2016, 5, https://doi.org/10.13171/mjc56/01607231833/desouza. 